\title{
PRESSURE DURING CURING AND THE STRENGTH OF 2024, 2017A AND 1050 ALUMINIUM ALLOY SHEET ADHESIVE JOINTS
}

\author{
Anna Rudawska' \\ 1 Department of Production Engineering, Faculty of Mechanical Engineering, Lublin University of Technology' \\ Nadbystrzycka 36, 20-618 Lublin, Poland, e-mail: a.rudawska@pollub.pl
}

Received: 2015.04.10

Accepted: 2015.05.08

Published: 2015.06.01

\begin{abstract}
This paper is primarily devoted to one of adhesive curing process parameters - pressure applied during curing, as well as the type of adhesive. The aim of this work is to determine the influence of pressure applied during curing process of aluminium alloy sheet adhesive joints on the strength of adhesive joints formed with two epoxy adhesives: Loctite 9484 and Loctite 9466 . Three types of aluminium alloy sheets were tested, namely AW 2024, AW 2017A and AW 1050, applied in many branches of engineering. During formation of adhesive joints, other conditions remained unchanged, and surface preparation operations included mechanical processing and degreasing.
\end{abstract}

Keywords: adhesive joint strength, pressure, curing, aluminium alloys.

\section{INTRODUCTION}

Adhesive joining significantly supplements other methods of joining structural materials. Nowadays, adhesive technology is used in multiple branches of industry: building engineering, automotive and aircraft industries, machine construction, packaging production and many more. Joining metals by adhesive joining is becoming increasingly commonplace due to several factors, such as: considerable strength of joints, vibration damping, joining different structural materials, frequently of substantially disproportionate in geometric dimensions [1-4].

The adhesive bonding technology comprises several consecutive technological operations. Individual operations may consist of a number of stages, be characterised by specific technological parameters, involve diverse equipment and instrumentation. Detailed conditions of adhesive bonding operation are chosen based on, inter alia, the type of adherends, the type of adhesive, geometry of elements and structures, joint forming conditions etc. [2, 3, 5-7].

The article presents some aspects of curing process: the influence of pressure on the strength of adhesive joint strength. A lot of authors are pre- senting various kinds of problems of curing process, adhesives, ageing in various environments, etc. [5, 8]. S.G. Prolongo and others [5] presented the study of adhesive properties of different epoxy resin and among others things analyse of the curing reaction. Borsellino and others [9] analysed for example the effect of curing time of resins on the mechanical properties of the composite joints. Curing constitutes one of technological factors considerably influencing adhesive joint strength. Adams and others [10] presented the effect of temperature on the strength of adhesive. Stewart, Chambers and Gordon [11] described the cohesive performance of an epoxy adhesive as a function of cure level.

\section{PRESSURE DURING CURING PROCESS}

Pressure is another technological parameter of adhesive layer curing. Pressure in adhesive bonding process enhances wetting process, particularly when filling micropores and microirreguralities of the surface is involved. It facilitates spreading the adhesive and fixing the position of adhered elements. The adjustment of curing pressure depends on the adhesive (its thickness, viscosity, thermal 
shrinkage, chemical shrinkage), the type of joined materials and surface preparation methods. Additionally, size, shape, thickness and position of the adhesive joint itself plays a crucial role in adhesive joint construction $[2,3,12]$.

Pressure applied during adhesive bonding should ensure a close contact between the joined surfaces as well as optimal thickness of adhesive layer $(0.05-0.20 \mathrm{~mm})[1,2]$. Pressure conditions thickness of adhesive layer, which in high-reliability constructions is a critical requirement.

In many instances, excessive pressure force or inappropriate arrangement of pressure pads on the adhesive bonded joint may lead to deformation of joined structures. The value of the applied pressure depends on whether the adhesive solidifies as a consequence of condensation polymerisation (pressure of $1 \mathrm{MPa}$ ), or in another way (pressure of $0.05 \mathrm{MPa}$ ) [2].

Required pressure may be applied with the use of different equipment. In aircraft structures, different types of joints may be cured in autoclaves of different structure and overall dimensions depending on the dimensions of the joined structure. The curing method depends on the type of adhesive, the type of structure, applied pressure and operating conditions $[2,3]$.

Adhesives consisting of epoxy resins cured with different types of curing agents are among the most common adhesive compositions $[2,11]$. Epoxy resins cross-link (set) as epoxy or hydroxyl groups in the resins react with amines or acid anhydrides. Epoxy resin curing agents are chemical compounds, which, as a result of chemical reactions, cause spatial cross-linking of resins imparting properties of adhesive, saturant or chemosetting plastics to them [13].

\section{EXPERIMENTAL TESTS}

Experimental tests consisted in forming 6 variants adhesive single-lap joints of AW2024, AW2017A and AW1050 aluminium alloy sheets. Two types of epoxy adhesives of different properties were used. Furthermore, for each adhesive, five variants of pressure value applied were tested. Following specified seasoning time adhesive joints were subjected to strength tests.

\section{Materials and adhesive joints characteristic}

The research consisted in testing singlelap adhesive joints of AW2024, AW2017A and
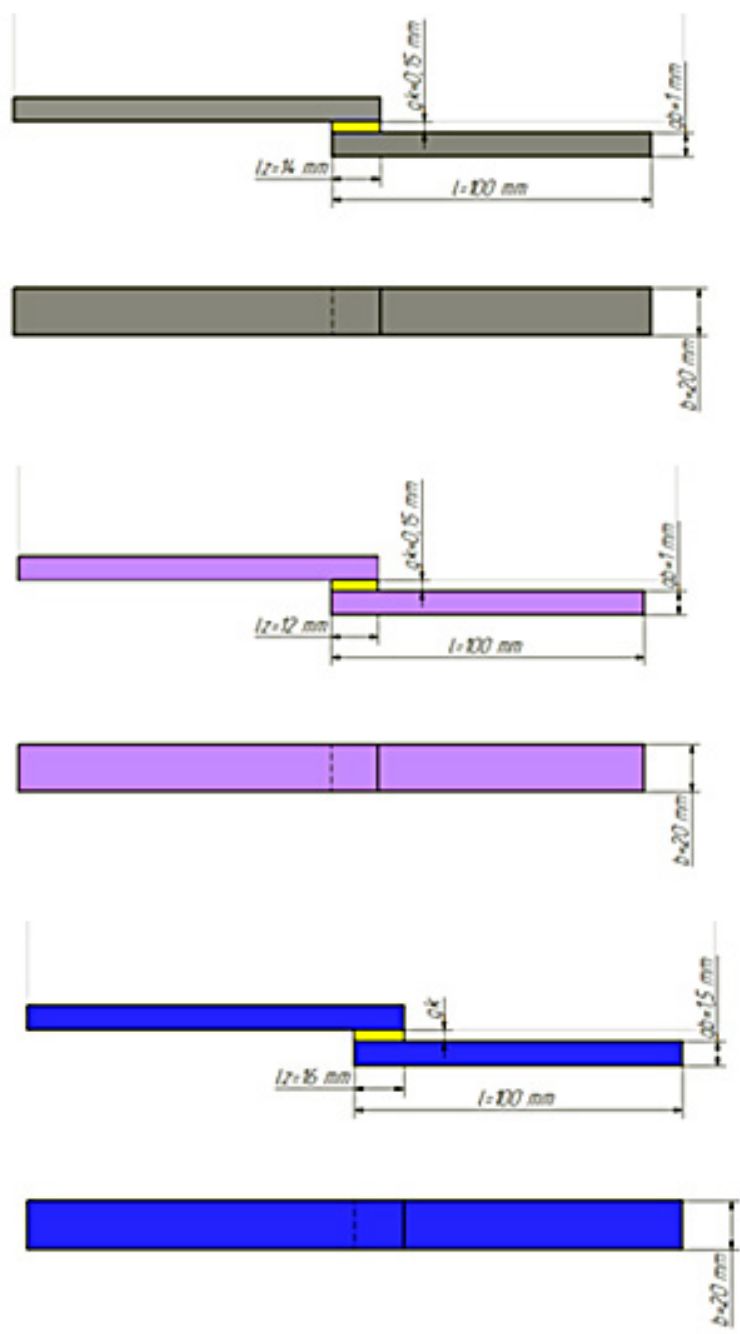

Fig. 1. Size and dimensions of tested adhesive specimens: a) AW 2024, b) AW 2017A, c) AW1050

AW1050 aluminium alloys, the geometry of which is presented in Figure 1.

Thickness and length of adherends were identical for all tests and equal to $b=20 \pm 0,11 \mathrm{~mm}$ and $l=100 \pm 0,8 \mathrm{~mm}$ respectively. The thickness of adhesive layer was determined in experimental tests.

\section{Adhesives characteristic}

Adhesive joints of aluminium alloys were formed with two types of two-component epoxy adhesives: Loctite 9466 and Loctite 9484, the selected properties of which are presented in Table 1 (for cured material) $[14,15]$.

Adhesives Loctite 9466 and 9484 require 24 hours in room temperature in order to produce high strength. The process, however, can be accelerated by applying higher temperature.

Adhesive compositions tested in experimental study contain an identical chemical resin compound - epoxy, yet differ in terms of the curing 
Table 1. Selected properties of applied adhesive (cured material)

\begin{tabular}{|c|l|c|c|}
\hline \multirow{2}{*}{ No. } & \multicolumn{2}{|c|}{ Properties } & \multicolumn{2}{c|}{ Adhesive } \\
\cline { 3 - 4 } & & $\begin{array}{c}\text { Loctite } \\
9466\end{array}$ & $\begin{array}{c}\text { Loctite } \\
9484\end{array}$ \\
\hline 1 & Tensile Strength, ISO 527-3, N/mm & 32 & 15 \\
\hline 2 & Tensile Modulus, ISO 527-3, N/mm & 1718 & 161 \\
\hline 3 & Shore Hardness, ISO 868, Durometer D & 60 & 55 \\
\hline 4 & Elongation, ISO 527-3, \% & 3 & 50 \\
\hline
\end{tabular}

agent chemical type, which results in their different properties. Different curing agent requires different adhesive components mixing ratio by volume and by weight. Another factor taken into particular consideration was the working time of the adhesive, which necessitated performing joints within a couple of minutes after mixing the components of adhesives. Moreover, attention was given to the amount of adhesive mixed, due to the fact that excessive amounts of adhesive and ambient temperature above $22{ }^{\circ} \mathrm{C}$ contribute to shortening the working time, owing to, inter alia, emitting excessive amounts of heat.

Adhesives used in the tests are delivered in dual packages (cartridges), facilitating dosing and preparation. Mixing and dosing was performed with special dispensing device - a double syringe and a static mixer. After mixing the adhesive was applied on one of the adhered surfaces.

\section{Joint forming conditions}

The surface of adhered alloy sheets was prepared as follows:

- the first stage consisted in degreasing with acetone in order to remove any surface contaminants,

- the second stage was mechanical working with P400 grit abrasive discs,

- finally, degreasing of the surfaces with acetone was repeated.

Degreasing agent evaporation time equalled 3 minutes and was followed by applying the prepared adhesives. The cold-setting process was conducted at $21{ }^{\circ} \mathrm{C}$. Five variants of pressure were applied during curing, respectively: $0.016 \mathrm{MPa} ; 0.032$ $\mathrm{MPa} ; 0.048 \mathrm{MPa}$; $0.064 \mathrm{MPa}$ and $0.080 \mathrm{MPa}$. Adhesive joints were formed at relative air humidity between 22-23\%. Prepared adhesive joints of the analysed sheets are presented in Figure 2.

Adhesive joints conditioning time was 6 days (at temperature and humidity conditions identi- cal to joint forming), followed by strength tests, allowing to determine joint failure force values, thus adhesive joint strength.

Tests were conducted on a test stand - materials testing machine Zwick/ Roell Z150 according to standard DIN EN 1465. Figure 3 shows a model view of a tested adhesive joint test sample.

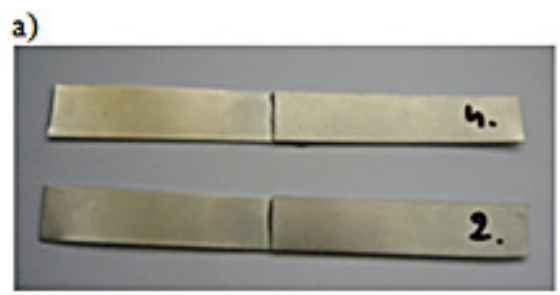

b)

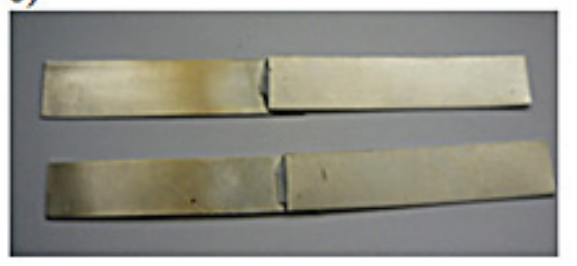

c)

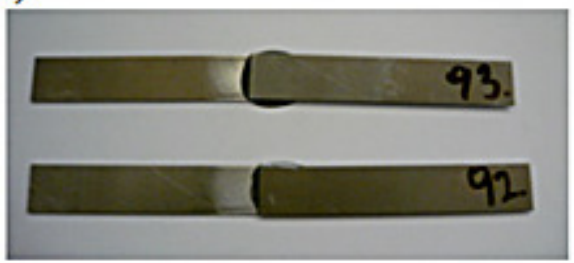

Fig. 2. Aluminium alloy sheet adhesive joints: a) AW 2024, c) AW 2017A, b) AW 1050
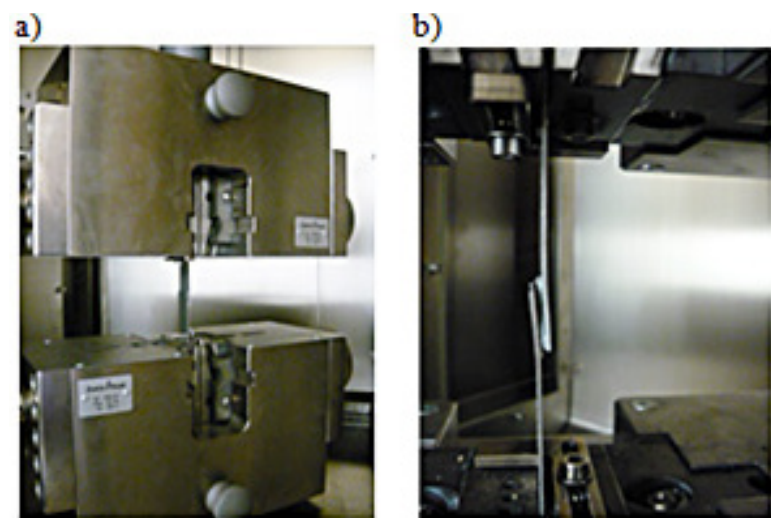

Fig. 3. The view of: a) wedge-screw grips with a test sample prior to destructive tests, b) grips with a test sample after failure

\section{TEST RESULTS - ADHESIVE JOINTS STRENGTH}

\section{AW 2024 aluminium alloy}

Strength test results of AW 2024 aluminium alloy sheet adhesive joints, formed with the ana- 
lysed epoxy adhesives, at different pressure applied during curing, are shown in Figures 4 and 5.

Based on test results presented in Figure 8, it was observed that the highest joint strength $(23 \mathrm{MPa}$ ) was achieved in the case of $0.048 \mathrm{MPa}$ pressure applied during curing. For the pressure of $0.080 \mathrm{MPa}$, the second highest strength value was achieved - 21.50 MPa. In the remaining cases strength values obtained varied insignificantly, therefore the value of pressure applied during curing is of little influence on strength.

The study of test results (Fig. 5) reveals that in the case of joints formed with Loctite 9484 no significant impact of pressure applied during curing on joint strength can be observed for the first four pressure variants. The last variant $(0.080 \mathrm{MPa})$ produced the highest joint strength $-9.66 \mathrm{MPa}$.
Based on the conducted tests it may be concluded that Loctite 9466 adhesive provides higher joint strength than 9489 (Fig. 4 and Fig. 5). In each variant of pressure applied during curing the strength manifested by joints formed with Loctite 9466 proved twice, and for two variants even three times as high as an analogical 9484 adhesive joint. The differences for tested pressure values are as follows: $0.016 \mathrm{MPa}-127 \% ; 0.032 \mathrm{MPa}-128 \% ; 0.048 \mathrm{MPa}$ $-215 \% ; 0.064 \mathrm{MPa}-108 \%$; $0.080 \mathrm{MPa}-123 \%$.

\section{AW 2017A aluminium alloy}

Strength test results of AW 2017A aluminium alloy sheet adhesive joints, formed with the analysed epoxy adhesives, at different pressures applied during curing, are shown in Figures 6 and 7.

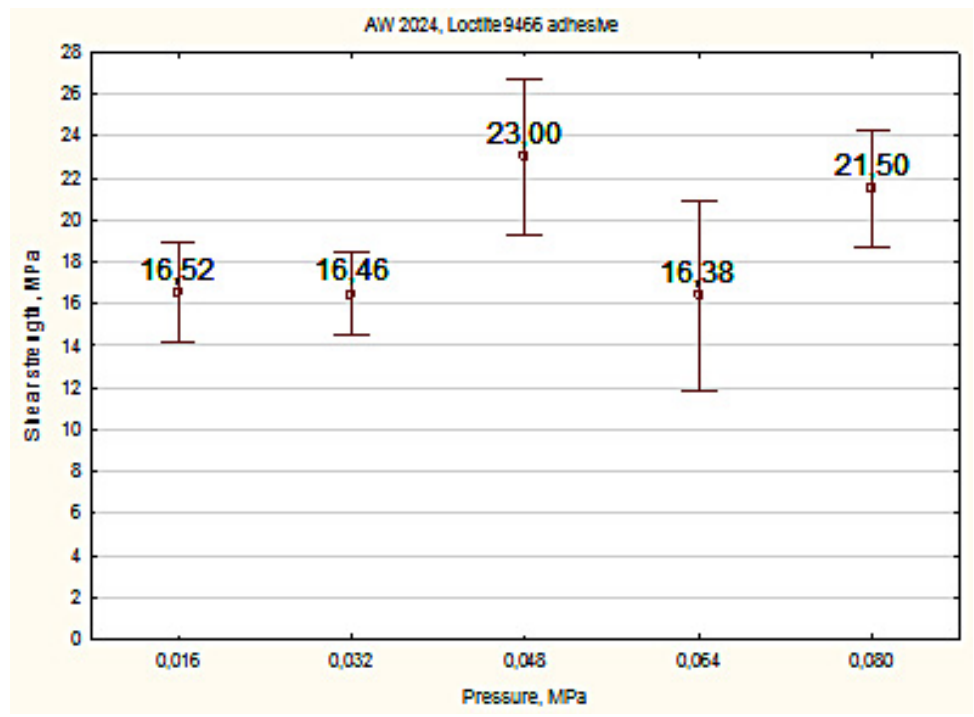

Fig. 4. Shear strength of 2024 aluminium alloy sheet adhesive joints formed with 9466 adhesive, depending on pressure value

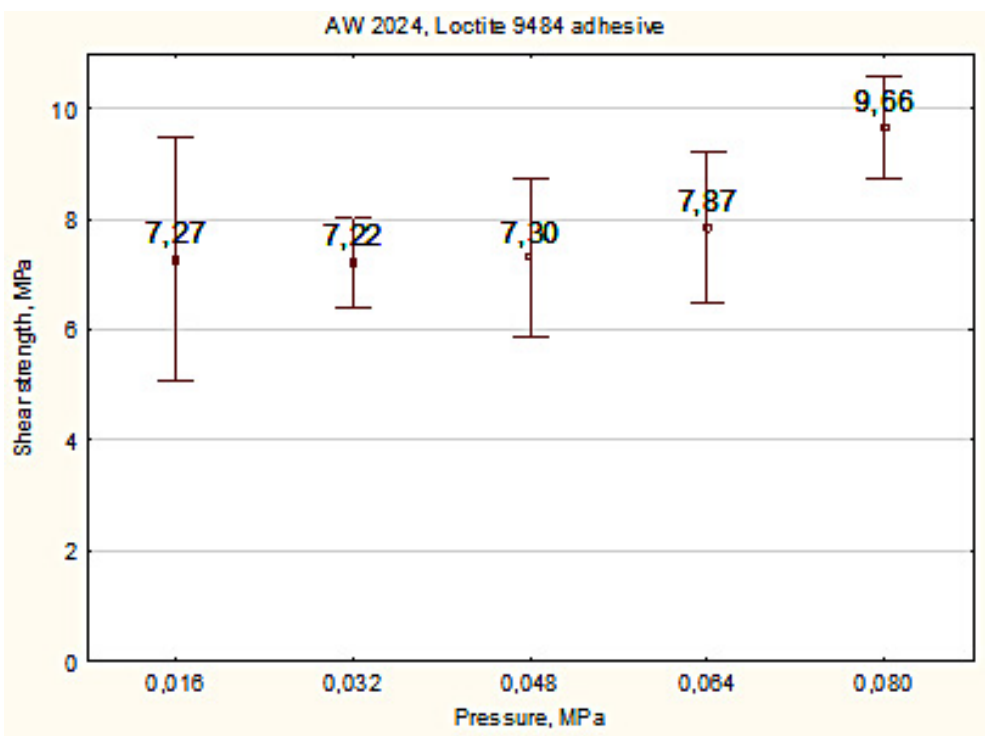

Fig. 5. Shear strength of adhesive joints formed with 9484 adhesive, depending on pressure value 


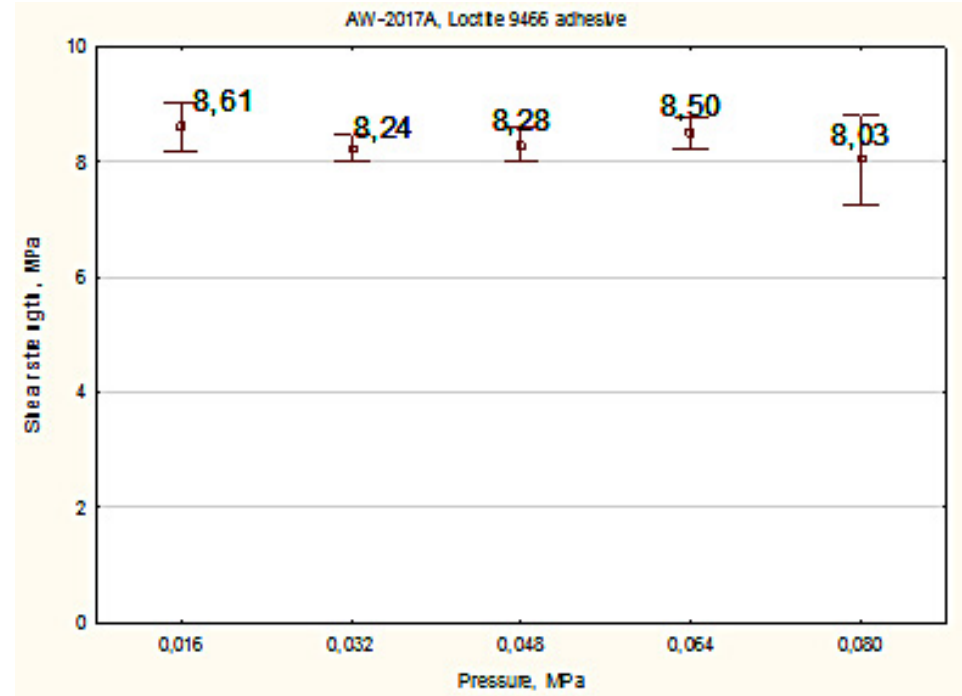

Fig. 6. Shear strength of AW 2017A aluminium alloy sheet adhesive joints formed with 9466 adhesive, depending on pressure value

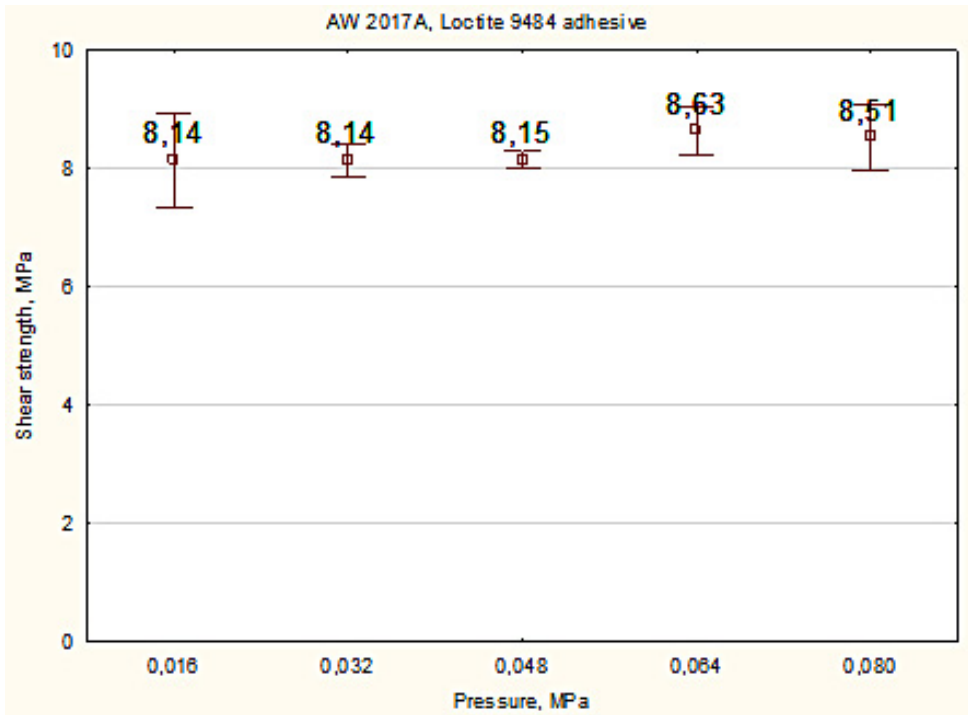

Fig. 7. Shear strength of AW 2017A aluminium alloy sheet adhesive joints formed with 9484 adhesive, depending on pressure value

Based on test results (Fig. 6 and Fig. 7), it was noticed that applying both epoxy adhesives produces similar joint strength values. Moreover, no influence of pressure applied during curing on the strength of 2017A aluminium alloy sheet adhesive joint was observed.

\section{AW 1050 aluminium alloy}

Strength test results of AW 1050 aluminium alloy sheet adhesive joints, formed with the analysed epoxy adhesives, at different pressures applied during curing, are shown in Figures 8 and 9.

Analysing the test results (Fig. 9) it was observed that the highest joint strength $(20.25 \mathrm{MPa})$ was obtained for the pressure of $0.032 \mathrm{MPa}$, and the lowest strength in the case of the highest pressure applied - $0.080 \mathrm{MPa}$. Moreover, it was noticed that joint strength increases up to the pressure value of $0.032 \mathrm{MPa}$ after which point it decreases with the increase of pressure applied during curing. It may be concluded therefore that there exists an optimum pressure value where the strength of the joint is the highest.

\section{Examples of joint failure}

Examples of test samples following failure tests with two epoxy adhesives are presented in Figures 10-12. Analysis proves that it can be observed adhesive-cohesive failure of adhesive layer. 


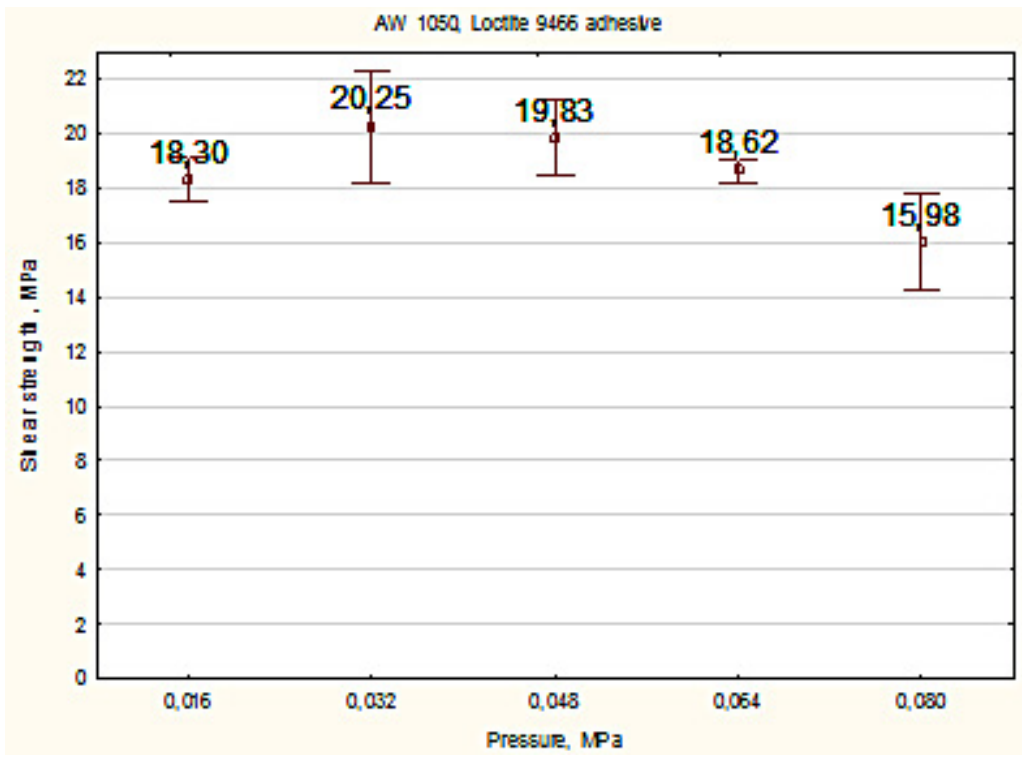

Fig. 8. Shear strength of AW 1050 aluminium alloy sheet adhesive joints formed with 9466 adhesive, depending on pressure value

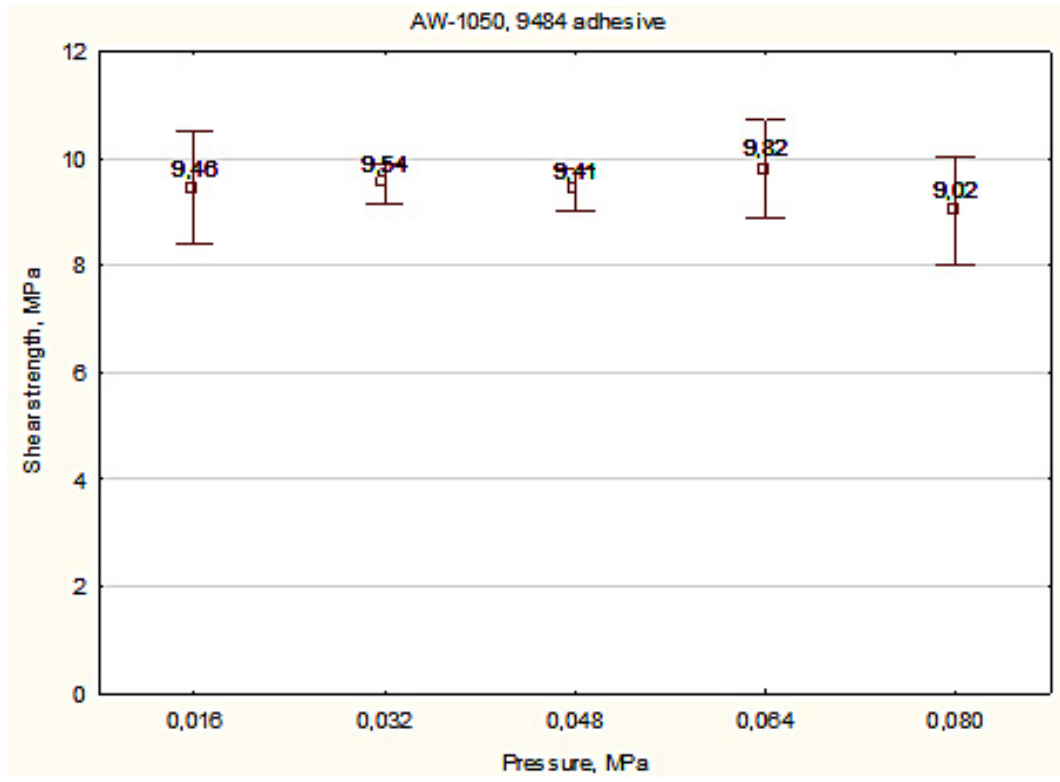

Fig. 9. Shear strength of 1050 aluminium alloy sheet adhesive joints formed with 9484 adhesive, depending on pressure value

a)

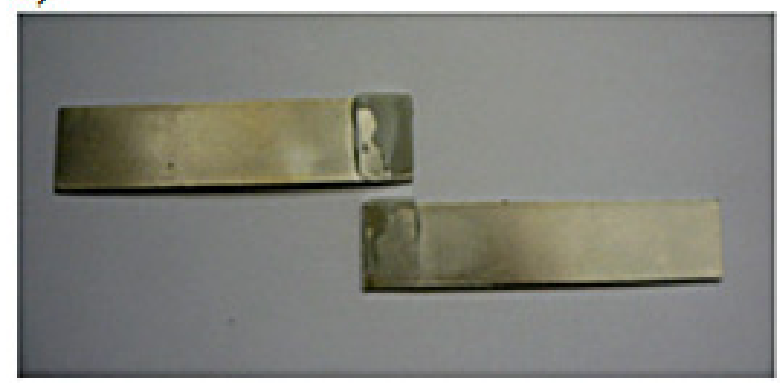

b)

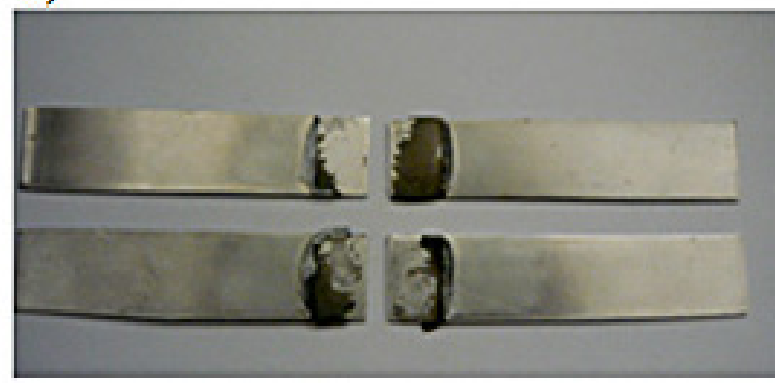

Fig. 10. Failure adhesive joints of AW 2024 aluminium alloy sheets formed with adhesives:

a) Loctite 9466, b) Loctite 9484 
a)

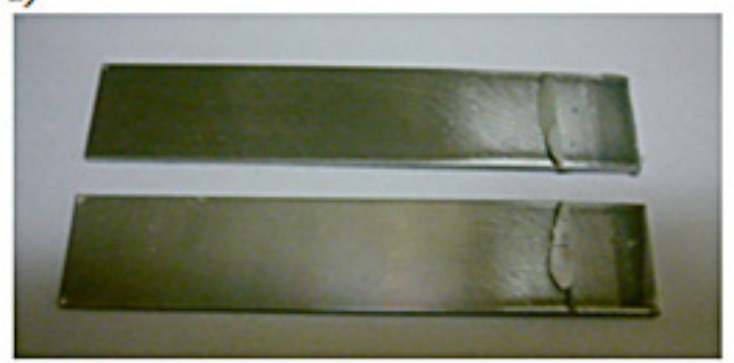

b)

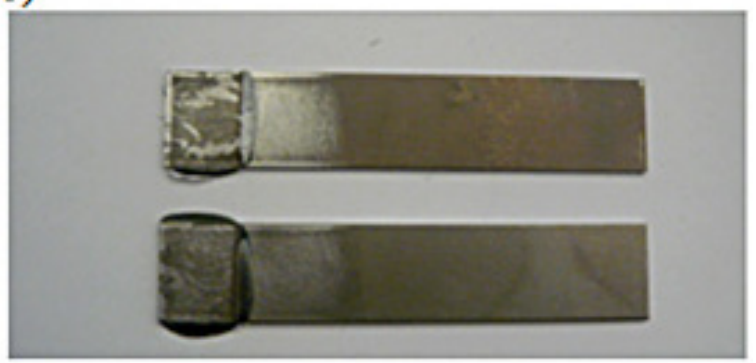

Fig. 11. Failure adhesive joints of AW 1050 aluminium alloy sheets formed with adhesives:

a) Loctite 9466, b) Loctite 9484

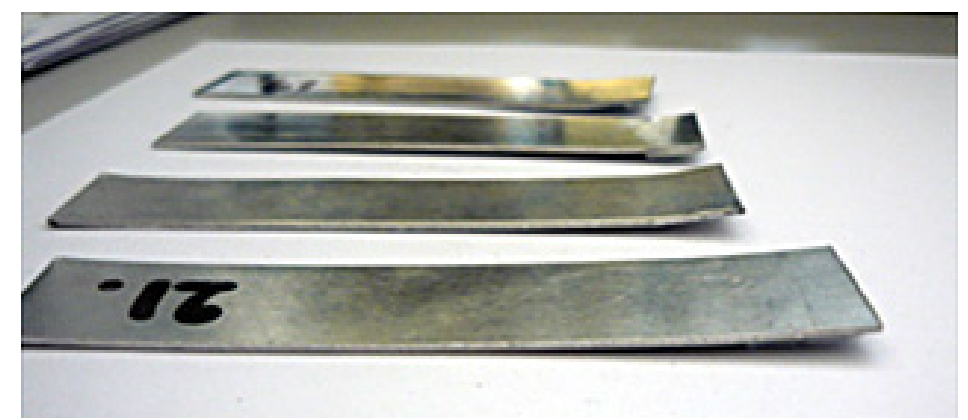

Fig. 12. Failure adhesive joints of AW 2017A aluminium alloy sheets

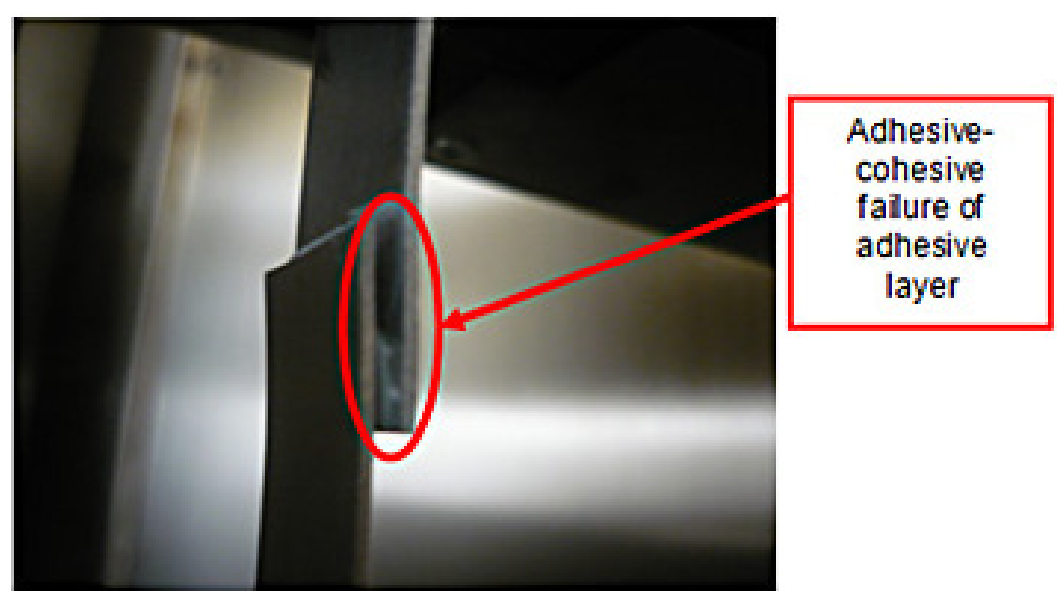

Fig. 13. AW1050 aluminium alloy sheet adhesive joints following strength test

Figure 13 shows adhesively joined AW 1050 aluminium alloy sheets in the materials testing machine clamping jaws, after a strength test. Characteristic shape of failure samples as well as adhesive and cohesive adhesive layer failure can be seen.

\section{CONCLUSIONS}

The study presented in the paper was oriented towards determining the impact of pressure value on the strength of adhesive joints of AW 2024, AW 2017A and AW1050 aluminium alloy sheets, formed with epoxy adhesives.
Analysing the obtained aluminium alloy sheet adhesive joints strength, nearly double difference in strength values of the analysed sheet joints formed with tested adhesives can be observed, nota bene, these were the joints formed with Loctite 9466 which were characterised by higher strength throughout the research. This applies to AW 2024 and AW 1050 aluminium alloy sheets joints. The highest strength values for the materials in question were noted for the pressure of $0.048 \mathrm{MPa}$ and $0.032 \mathrm{MPa}$ respectively. It may be therefore concluded that in the case of joining analysed aluminium alloy sheets the preferred choice of adhesive should be epoxy adhe- 
sive Loctite 9466, due to higher strength bond it creates. For these joints bigger differences in adhesive strength values were observed than for Loctite 9484, for which neither pressure value nor adhesive joint thickness has a significant impact on obtained joint strength. Finally, in the case of AW 2017A aluminium alloy sheets samples, the selection of adhesive was not a factor, as strength values for both tested adhesives were comparable. The presented conclusion is based on the analysed scope of pressure applied in tests.

Application of Loctite 9484 is advantageous in as much as this adhesive offers similar joint strength regardless of pressure applied during curing. This concerns all tested aluminium alloy sheets: AW 2024, AW 2017A and AW 1050. Moreover, it has been observed that the strength of adhesive joints formed with Loctite 9484 of three analysed aluminium alloy sheets was comparable regardless of tested adherend. It appears reasonable to conclude that the application of this adhesive to form aluminium alloy sheet joints will ensure little impact of the aforementioned factors (pressure) on the strength of these joints.

In conclusion, it is possible to select optimum pressure value which will ensure highest joint strength. In addition, for certain coldsetting adhesives applied pressure will not be of great impact, in the analysed scope, on the strength of adhesive joints. Therefore, with a view to increasing joint strength, while analysing technological factors attention must be paid to other factors as well.

\section{REFERENCES}

1. Godzimirski J.: The strength of constructional bonding joints. Printed by WNT, Warszawa 2002.

2. Godzimirski J., Kozakiewicz J., Łunarski J., Zielecki W.: The constructional bonding joint of metal elements in machine building. Printed by Rzeszow Technical University, Rzeszow 1997.

3. Arenas J.M., Narbón J.J., Alía C.: Optimum adhesive thickness in the structural adhesives joint using statistical techniques based on Weibull distribution. International Journal of Adhesion and Adhesives, 30, 2010, 160-165.

4. Critchlow G.W., Yendall K.A., Bahrani D., Quinn A., Andrews F.: Strategies for the replacement of chromic acid anodizing for the structural bonding of aluminium alloys. International Journal of Adhesion and Adhesives, 26, 2006, 419-453.

5. de Morais A.B., Pereira A.B., Teixeira J.P., Cavaleiro N.C.: Strength of epoxy adhesive-bonded stainless-steel joints. Journal of Adhesion Science and Technology, 27, 2007, 679-686.

6. Rudawska A., Kuczmaszewski J.: The bonding of zinc coated sheets. Printed by Lublin Technical University, Lublin 2005.

7. Rudawska A., Kowalska B., Garbacz T.: The influence of the type of adhesives on low-density polyethylene bonded joints strength. Conference materials. $27^{\text {th }}$ Polymer Processing Society, Annual Meeting. 10-14.05.2011 Maroko, Marrakesz.

8. Moussa O., Vassilopoulos P., de Castro J., Keller T.: Early-age tensile properties of structural epoxy adhesives subjected to low-temperature curing. International Journal of Adhesion and Adhesives 35, 2012, 9-16.

9. Borsalino C., Calabrese L., Di Bella G., Valenza A.: Comparisons of processing and strength properties of two adhesive systems for composite joints. International Journal of Adhesion and Adhesives, 27, 2007, 446-457.

10. Adams R.D., Coppendale J., Mallick V., Al.-Hamdan H.: The effect of temperature on the strenght of adhesive joint. International Journal of Adhesion and Adhesives, 12, 1992, 2185-190.

11. Stewart I., Chambers A., Gordon T.: The cohesive mechanical properties of a toughened epoxy adhesive as a function of cure level. International Journal of Adhesion and Adhesives, 27, 2007, 277-287.

12. da Silva L.F.M., Adams R.D.: Adhesive joint at high and low temperatures using similar and dissimilar adherends and dual adhesives. International Journal of Adhesion and Adhesives, 27, 2007, 216-226.

13. http://www.zch.sarzyna.pl (June 2012).

14. http://tds.loctite.com (June 2012).

15. http://www.akd-tools.gr (June 2012). 